\title{
A comparison of supervised, unsupervised and synthetic land use classification methods in the north of Iran
}

\author{
M. Mohammady $\cdot$ H. R. Moradi $\cdot$ H. Zeinivand $\cdot$ \\ A. J. A. M. Temme
}

Received: 1 August 2013/Revised: 18 August 2014/Accepted: 22 November 2014/Published online: 16 December 2014

(C) Islamic Azad University (IAU) 2014

\begin{abstract}
Land use classification is often the first step in land use studies and thus forms the basis for many earth science studies. In this paper, we focus on low-cost techniques for combining Landsat images with geographic information system approaches to create a land use map. In the Golestan region of Iran, we show that traditional supervised and unsupervised methods do not result in sufficiently accurate land use maps. Therefore, we evaluated a synthetic approach combining supervised and unsupervised methods with decision rules based on easily accessible ancillary data. For accuracy assessment, confusion matrices and kappa coefficients were calculated for the maps created with the supervised, unsupervised and synthetic approaches. Overall accuracy of the synthetic approach was $98.2 \%$, which is over the $85 \%$ level that is considered satisfactory for planning and management purposes. This shows that integration of remote sensing data, ancillary data and decision rules provides better classification accuracy than traditional methods, without significant additional use of resources.
\end{abstract}

M. Mohammady · H. R. Moradi ( $₫)$

Department of Watershed Management Engineering, College of

Natural Resources and Marine Sciences, Tarbiat Modares

University, Mazandaran, Iran

e-mail: hrmoradi1340@yahoo.com

H. Zeinivand

Department of Range and Watershed Management Engineering, Lorestan University, Lorestan, Iran

A. J. A. M. Temme

Soil Geography and Landscape Group, Wageningen University,

Wageningen, The Netherlands
Keywords Land use classification - ISODATA . Maximum likelihood $\cdot$ Synthetic method $\cdot$ Ancillary data . Iran

\section{Introduction}

Up-to-date land use maps are very important to scientists, planners, resource managers and policy makers. Satellite images have been widely used over the past 20 years as a basis for such maps and to improve our understanding of land use and land cover changes (LUCC). Remote sensing technology is an effective tool for spatial data acquisition to maintain the sustainable management of natural resources and economical perspective (Cetin 2009). A range of satellites delivers images with varying spatial and temporal resolution. One of the best sources for land use studies is the Landsat series of satellites. Landsat data are useful for land surface mapping, change detection and monitoring (Cohen and Goward 2004; Alesheikh et al. 2007; Hansen et al. 2008; Masek et al. 2008; Cetin 2009). Landsat data are particularly applicable for land use classification on a regional scale because of their lower cost, longer history and higher frequency of archives than other remote sensing data sources (Rozenstein and Karnieli 2010). As a result, Landsat images have been successfully used to classify land use in a large variety of landscapes from homogeneous tropical landscapes to heterogeneous Mediterranean landscapes (Alrababah and Alhamad 2006; Koutsias and Karteris 2003; Manandhar et al. 2009; Schulz et al. 2010; Brandt et al. 2013; Sexton et al. 2013; Zegre et al. 2013). Landsat's spatial resolution is $30 \mathrm{~m}$. The Landsat sensors include the Landsat 5 Thematic Mapper (TM), the Landsat 7 enhanced thematic mapper plus (ETM+) and the Landsat 1-5 multispectral scanners 


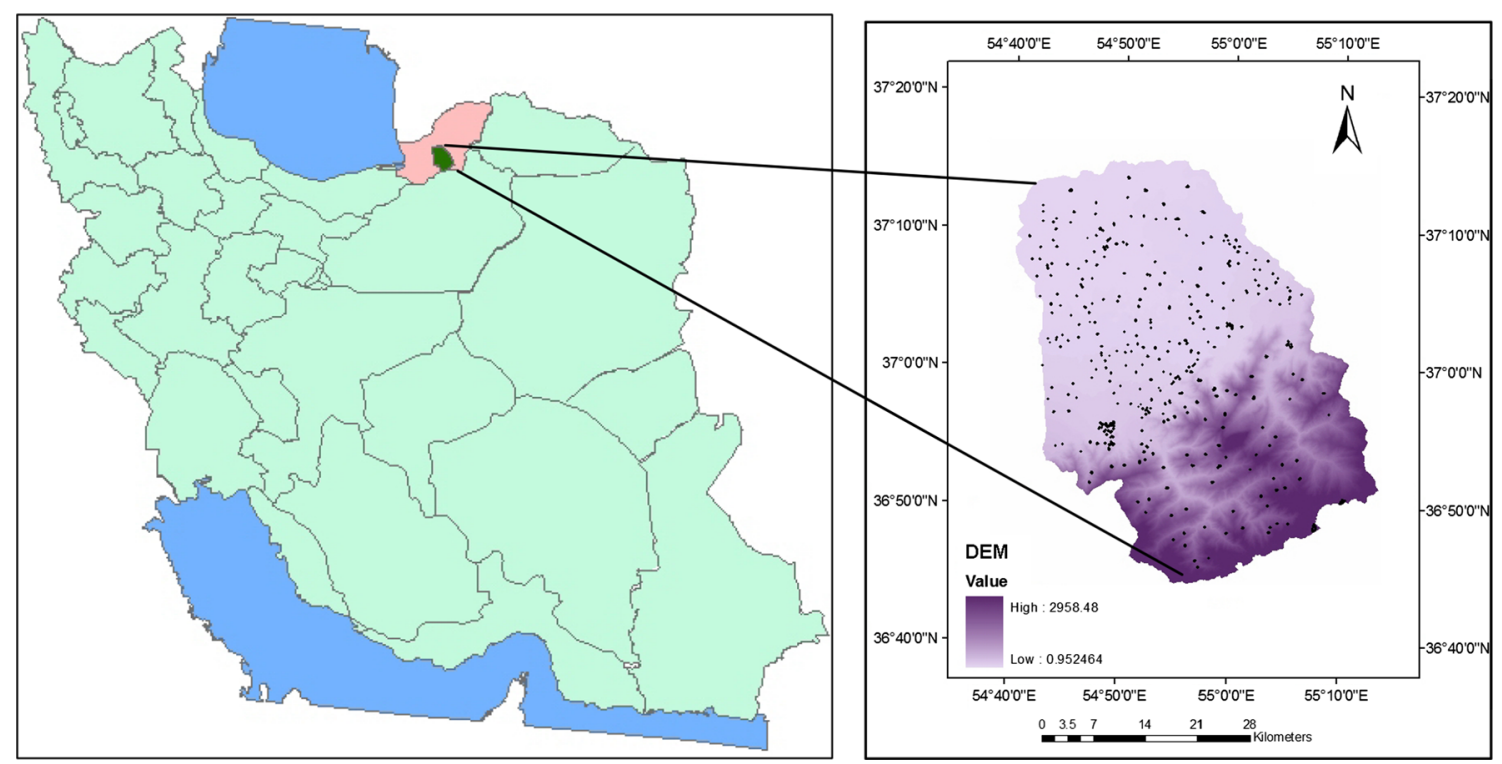

Fig. 1 Location of the Baghsalian watershed in the north of Iran

(MSS) (Chen et al. 2011). At the time of writing, two Landsat sensors are operational: TM on board Landsat 5 and ETM+ on board Landsat 7.

Several methods are available to map land use using satellite images. The simplest method is visual interpretation. This method is suitable in some limited cases, but visual interpretation is limited to a single-band or a three-band (red-green-blue) color composite, which means that not all available information is used. Moreover, visual interpretation is subjective and manual digitization of land use polygons is labor intensive. Therefore, automatic methods of mapping are more popular, especially for large areas (Rozenstein and Karnieli 2010). Automatic methods are divided into supervised and unsupervised methods, according to the need for information from the map's producers. It has been shown that in geomorphologically homogenous areas either of the automatic (supervised or unsupervised) methods can be successfully used for mapping, but in heterogeneous regions, it has been suggested that it is better to use synthetic methods (Lillesand and Kiefer 2000). Synthetic methods use additional maps next to satellite images to separate land use types with the same reflectance. This integration of remotely sensed data with other data sources such as previously existing land use data, geology, transportation network or digital elevation models (DEMs, with possibly derivatives such as slope and curvature) can result in higher classification accuracy (Manandhar et al. 2009; Stefanov et al. 2001; Shalaby and Tateishi 2007). Synthetic methods can take the form of decision rules that use data sources in combination
(Lillesand and Kiefer 2000). The objective of this study was to use and evaluate supervised, unsupervised and synthetic methods for land use mapping with a case study in the Baghsalian watershed in Iran. The study was carried out in March to June 2012 with financial support of Tarbiat Modares University. The main land use types in this watershed are broadleaf forest, conifer forest, rangeland, agricultural land, water bodies and residential land. The Baghsalian watershed is subject to natural hazards such as floods and landslides, which makes land use mapping essential in terms of future planning (Mohammady et al. 2012).

\section{Study area}

The Baghsalian watershed is in the north of Iran and covers approximately $1,800 \mathrm{~km}^{2}$. It lies between the latitudes $36^{\circ}$ $43^{\prime} 18^{\prime \prime}$ to $37^{\circ} 14^{\prime} 05^{\prime \prime} \mathrm{N}$ and the longitudes $54^{\circ} 43^{\prime} 24^{\prime \prime}$ to $55^{\circ} 16^{\prime} 52^{\prime \prime} \mathrm{E}$ in the southern part of the Golestan province, Iran (Fig. 1). The main cities in this watershed are Aliabad, Khan bebebin, Daland and Ramian. Altitude ranges from 0 to $2,950 \mathrm{~m}$ above $\mathrm{m}$.s.l. The study area is heterogeneous in terms of land use, terrain complexity and climatic regimes. In particular, the relations between reflectance and land use differ between the mountainous south and the flatter north of the watershed. Annual average temperature is $18{ }^{\circ} \mathrm{C}$, and the total annual rainfall is about $600 \mathrm{~mm}$, respectively. Rainfall varies between $390 \mathrm{~mm}$ in the south and $815 \mathrm{~mm}$ in the north of the watershed at Baghsalian and Zaringol meteorological stations, respectively (Golestan Regional Water Co 2007). 
Table 1 Data inventory

\begin{tabular}{llllllll}
\hline Data & TM & ETM+ & TM & TM & ETM+ & ETM+ & Topographical map \\
\hline Date & 2010.4 .3 & 2010.5 .29 & 2010.6 .6 & 2010.8 .9 & 2010.8 .17 & 2010.9 .2 & 1995 \\
\hline
\end{tabular}

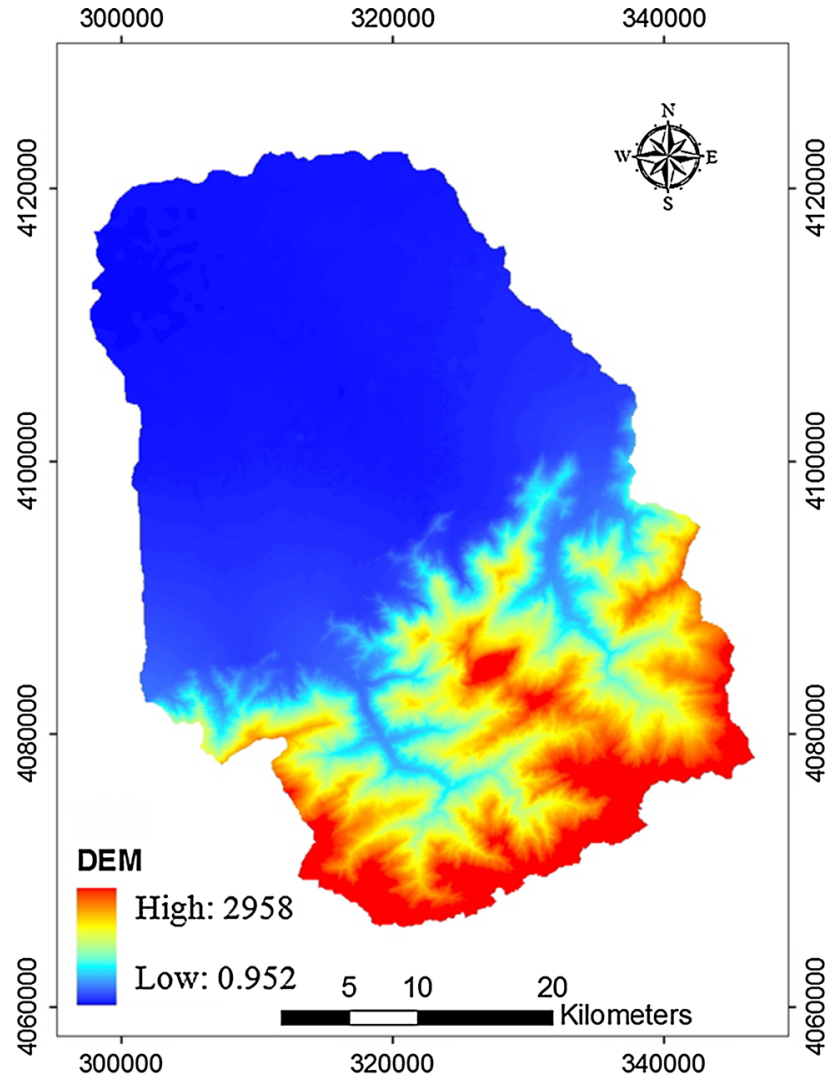

Fig. 2 DEM map of the Baghsalian watershed

\section{Materials and methods}

Data collection and image preprocessing

Six TM and ETM+ images from 2010 were prepared for the study area (path 162, row 34 and 35, Table 1). These images are freely available from the United States Geological Survey (USGS). Because of the scan-line corrector (SLC) failure for the ETM+ sensor on board Landsat 7, some pixels of each ETM+ image were missing (Abd elkawy et al. 2011). We applied a gap-fill algorithm to correct these images (Mohammady et al. 2013). Preprocessing of satellite images prior to land use classification is essential and has the unique goal of establishing a stronger linkage between the data and biophysical phenomena (Abd el-kawy et al. 2011). Satellite images were therefore geometrically corrected to the UTM projection (zone 40 north and with datum WGS 1984). Further preprocessing of the

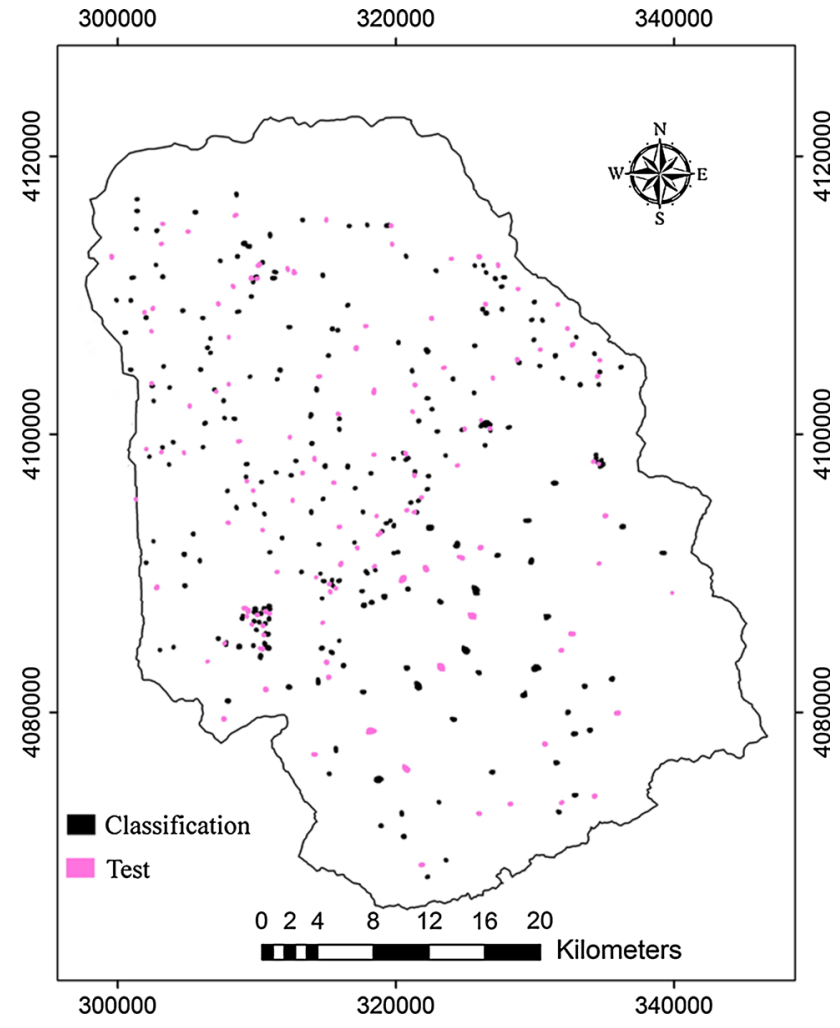

Fig. 3 Spatially distributed map of training samples

image included one-step radiometric and atmospheric corrections using the dark-object subtraction method (Rozenstein and Karnieli 2010). Additionally, a detailed $10 \mathrm{~m}$ contour map of the area at 1:25,000 scale was digitized. A DEM was prepared from this contour map (Fig. 2), and slope was derived from the DEM using ArcGIS 9.3 software. A Normalized Difference Vegetation Index (NDVI) was calculated from each satellite image. NDVI represents a measure of canopy greenness, and dense green vegetation canopies are generally greater than 0.6 (Wang et al. 2005; Maxwell and Sylvester 2012). An annual maximum NDVI image ( $\mathrm{NDVI}_{\mathrm{ann} \text {-max }}$ ) was generated for each year by taking the maximum NDVI value that occurred in the time series (Maxwell and Sylvester 2012).

Finally, 370 spectral signatures were collected from all land use types by field survey (GPS) where possible and by Google Earth in the more mountainous regions where forest is quite clearly distinguished on Google Earth (Chen et al. 2011; Brandt et al. 2013). It was attempted to divide the sample locations evenly over the research 
area (Fig. 3). These signatures located in the whole area with different slope and altitude. Minimum and maximum areas of signatures for classification were 3,857 and $47,250 \mathrm{~m}^{2}$, respectively. For signatures of test, these values were 4,072 and $38,121 \mathrm{~m}^{2}$. Slope of signatures was about 0 to $80 \%$, and the range of signature altitude was 0 to $2,700 \mathrm{~m}$. Figure 4 shows land use types in the study area including agriculture (A), broadleaf forest (B), residential area (C), conifer (D), rangeland (E) and water body $(\mathrm{F})$. In the modeling process, usually $2 / 3$ of data are used for modeling and the rest will be used for model test. We used 250 signatures for supervised classification and 120 signatures for accuracy assessment (Fig. 3). Table 2 shows the number of training samples per land use type. The number of signatures is dependent on difference of spectral characteristic and area of each land use types. In the homogeneous land use type, we decreased number of signatures and increased area of each signatures. For example, broadleaf forest covers about $35 \%$ of the study area, but the number of signatures is lower than residential area that covers about $2 \%$, because of difference of spectral characteristics of residential area compare to forest. Of course, area of signatures in the broadleaf forest is more than residential area.

\section{Classification}

Remote sensing image classification methods can be divided into unsupervised and supervised classification methods. For unsupervised classification, there is no need to have a prior understanding of the study area. Therefore, this method is time and cost efficient. The best-known variant of unsupervised classification is ISODATA, which groups pixels with similar spatial and spectral characteristics into classes (Bakr et al. 2010). However, for practical application, the quality of this classification is often not enough. Supervised classification methods therefore use
Fig. 4 Land use types in the study area
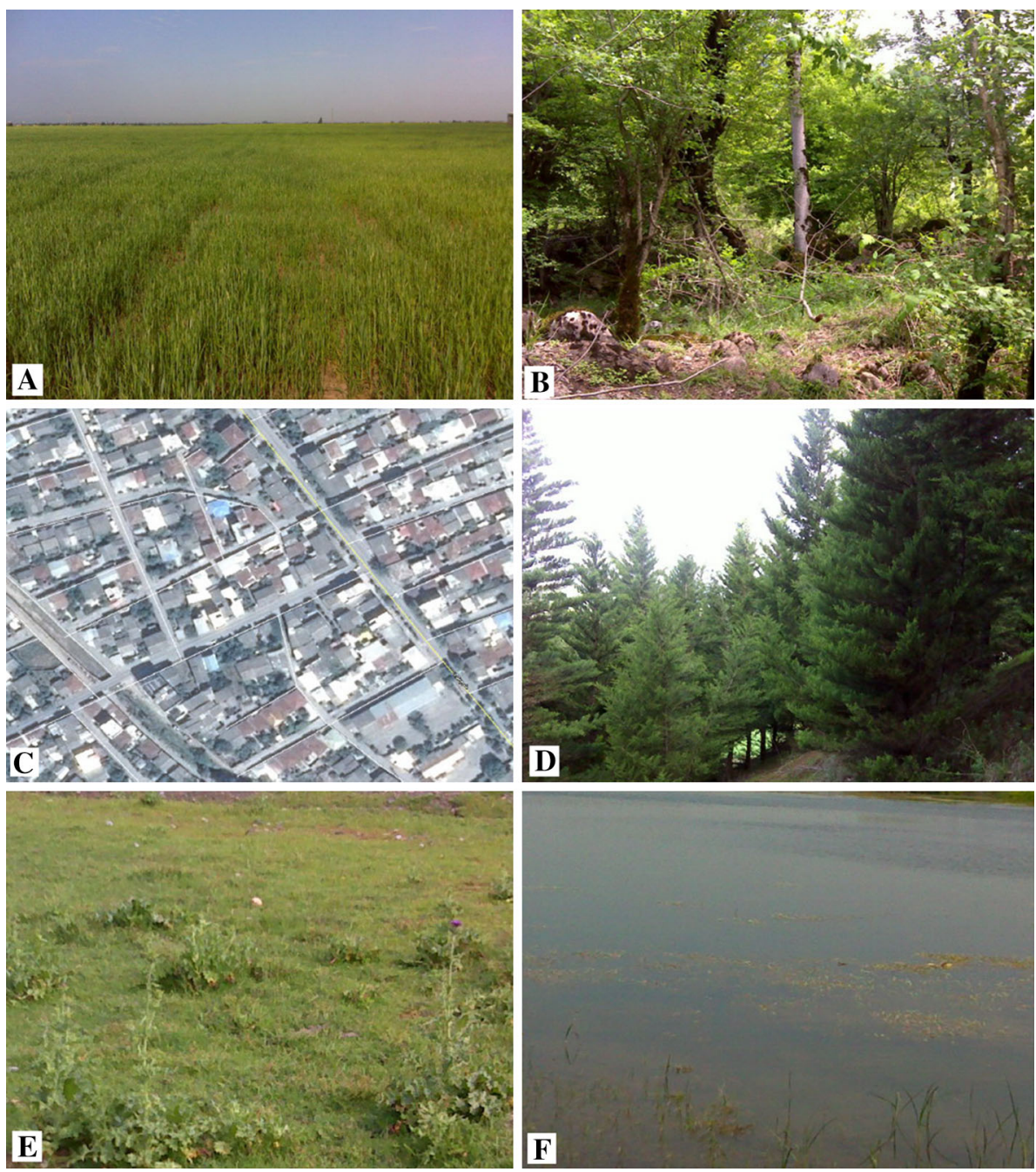
Table 2 Land use types of training samples

\begin{tabular}{llc}
\hline Land use types & Supervised classification & Accuracy assessment \\
\hline Agriculture & 91 & 44 \\
Broadleaf forest & 50 & 22 \\
Conifer forest & 15 & 8 \\
Rangeland & 18 & 10 \\
Residential area & 62 & 30 \\
Water body & 14 & 6 \\
\hline
\end{tabular}

prior knowledge, which often increases the classification accuracy (Yiqiang et al. 2010).

In the study area, cropping type changes seasonally and a close mix of agriculture with rangeland exists. It is therefore difficult to extract a land use map using only one satellite image. To attempt to solve this problem, we used a synthetic method where satellite imagery from multiple seasons is combined with ancillary data (Brandt et al. 2013). It was hoped that the added temporal information extractable from the multi-date imagery, and the decision rules governing the impact of the ancillary data resulted in a more correct land use classification.
The six TM and ETM+ images were first classified using both supervised (maximum likelihood) and unsupervised (ISODATA) methods with ENVI 4.8 software. Then, in the synthetic method, broadleaf forest, conifer forest, water bodies and residential areas were first derived from supervised classification. The spectral reflectance of these four land use types is relatively constant throughout a year, so that training signatures were a suitable basis for classification. Second, agricultural land use for each image was derived from unsupervised classification. There are several agriculture types in the Baghsalian watershed that have different reflectance, leading to difficulties with the traditional supervised classification. In addition, agriculture pixels significantly change their spectral signature between growth and fallow seasons. Therefore, we cannot use supervised classification to classify agriculture. We used spectral reflection and regular shape of agriculture (unsupervised classification) to extract this class. All agricultural land use types were then combined into one agricultural land use class. The remaining unclassified land was considered rangeland. For all land use types, expert knowledge of the area was then used in decision rules based on slope, altitude and NDVI maps to remove obvious classification errors.

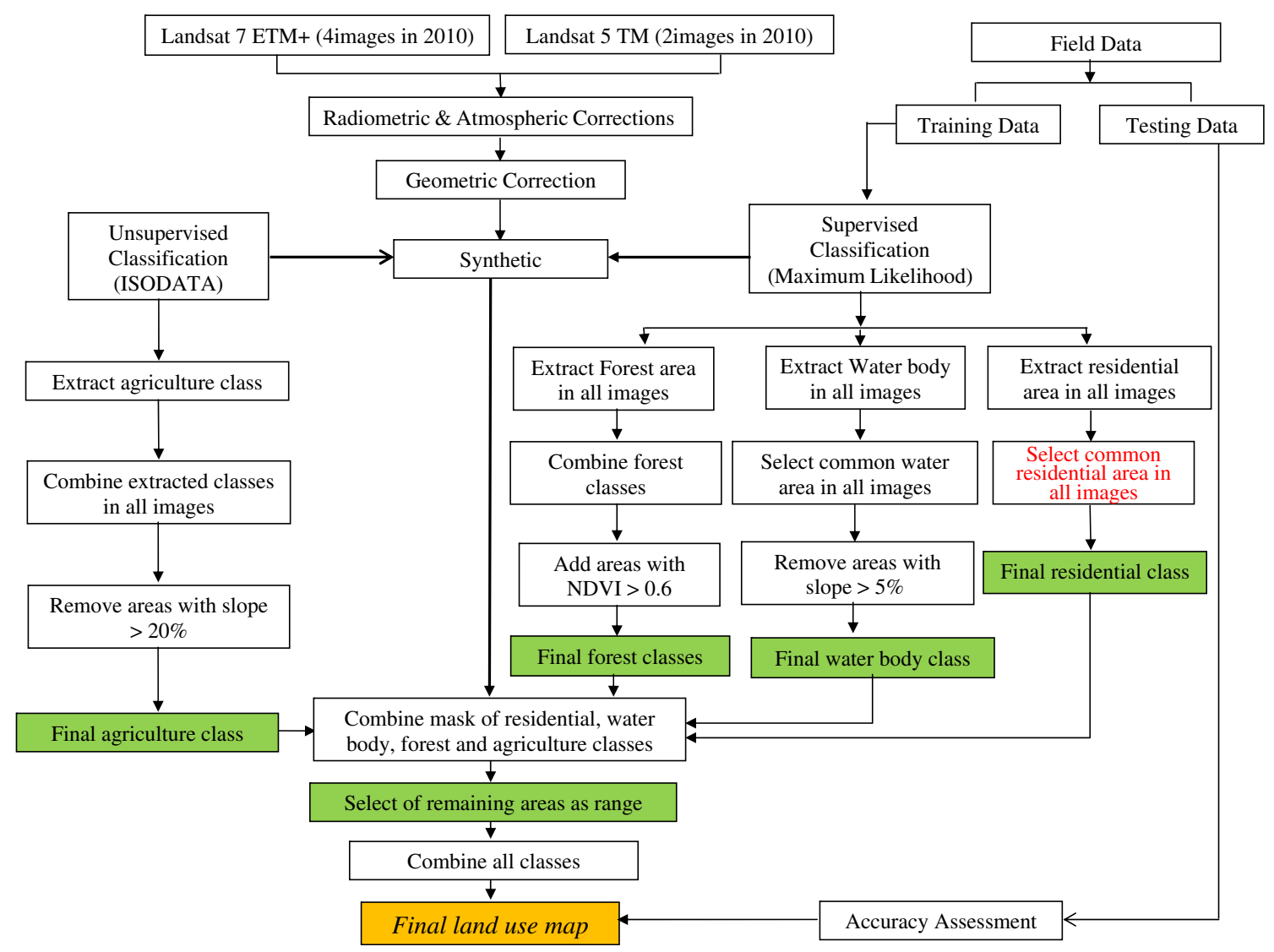

Fig. 5 Synthetic classification flowchart of Baghsalian watershed 
Finally, the separate set of 120 field observations that was not used in supervised classification was used to test the accuracy of the final (supervised, unsupervised and synthetic) land use maps.

Figure 5 shows a flowchart of the synthetic classification method and the important intermediate results.

\section{Agriculture class}

The reflective bands (1-5 and 7) of the images were used to classify agriculture classes with the unsupervised ISODATA classification technique (Bakr et al. 2010).

This method is particularly suited for the classification of agricultural land use, where fields with regular shape and green colors must be defined. The ISODATA output map, which has unique values for every regularly or irregularly shaped area, was compared with a false color composite where green areas show up in red. Regularly shaped areas in the ISODATA map that had high greenness according to the false color composite were considered agriculture. As an illustration of this, Fig. 6 shows an example false color composite and ISODATA map of the same date (2010.8.9).

This procedure was repeated with satellite images of different seasons to capture fields that were cropped in different seasons. There are six unsupervised maps and six agriculture maps extracted from unsupervised maps with a large number common in the total maps. Combining these maps adds pixels to final class of agriculture that are not common in the maps, so no miss any pixel of agriculture.

Forest, residential and water body classes

Maximum likelihood classification (MLC) was used for supervised classification (Bakr et al. 2010; Otukei and Blaschke 2010; Petropoulos et al. 2012; Rojas et al. 2013). MLC assumes that the statistics for each class in each band are normally distributed and then calculates the probability that a given pixel belongs to a specific class. MLC defines the means and variances of the classes from training samples, and then, those are used to compute the probabilities of belonging to a certain class for every pixel in the satellite image (Petropoulos et al. 2012). Using MLC, broadleaf forest, conifer forest, water bodies and residential areas were derived from images. This again resulted in six output maps per land use that have a large number of cells in common. Maps were combined in the same procedure as mentioned for agriculture. Finally, all extracted classes from the supervised and unsupervised methods were combined in ENVI software and the unclassified land was considered rangelands.

\section{Using ancillary map}

Ancillary maps were used to improve the accuracy of the land use map based on expert knowledge. Such expert
Fig. 6 False color composite (a) and ISODATA map (b) of Baghsalian watershed

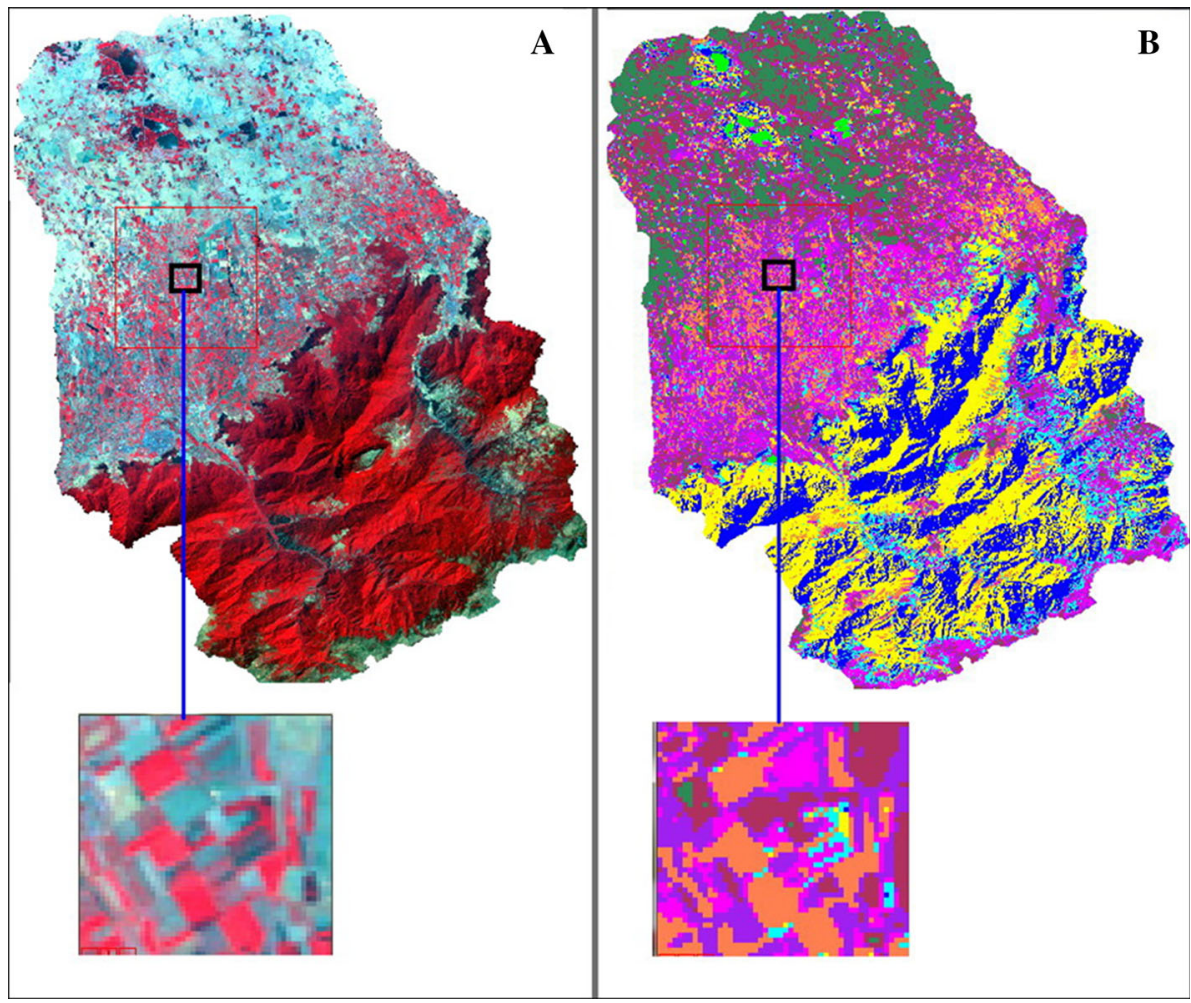




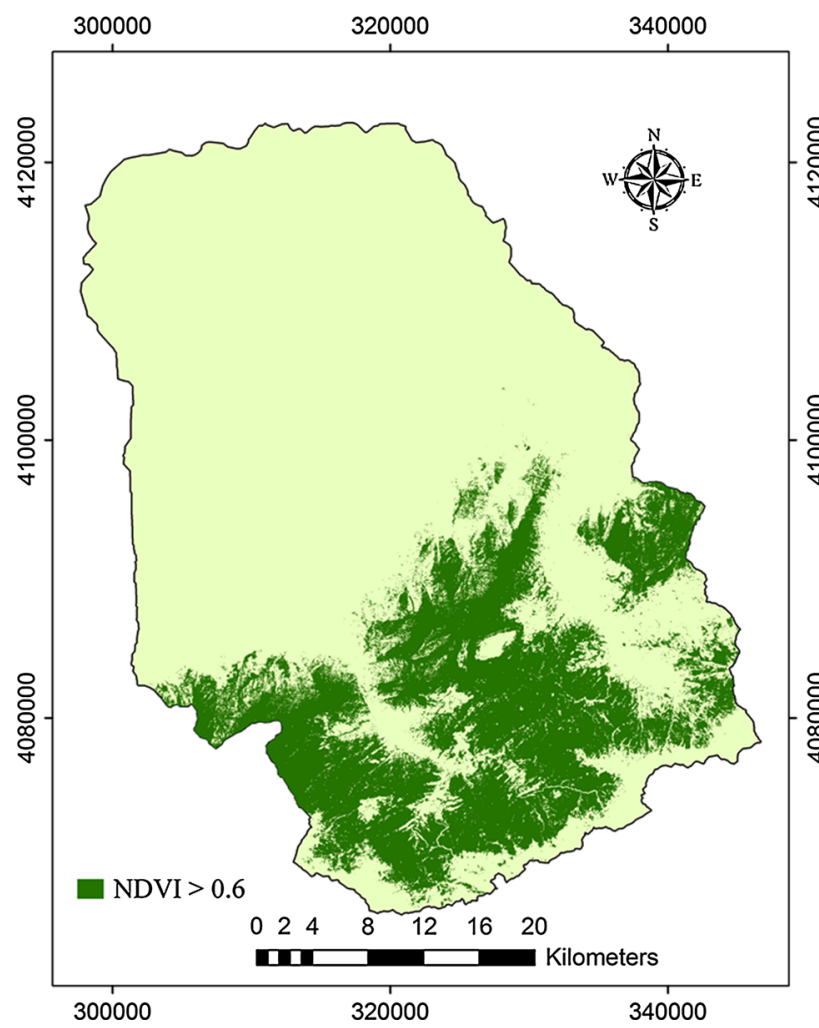

Fig. 7 NDVI map with value $>0.6$ in Baghsalian watershed

knowledge, summarized in decision support systems (DSS), can provide better classification accuracies than any of the individual data sources used alone (Rozenstein and Karnieli 2010). Ancillary maps of slope gradient, altitude and NDVI were used. Rules were then defined according to our knowledge of land use in the study area. To improve the classification of water bodies, cells with a slope more than $5 \%$ were removed from the areas that were initially classified as water, arguing that water should be in flat terrain. To improve the classification of both forest classes (broadleaf and conifer forest), the NDVI map was used (Fig. 7). Areas classified as non-forest with NDVI higher than 0.6 were considered forest and were added to the previous map of forest class because it has been observed that only forest has NDVI values over 0.6 (Wang et al. 2005; Maxwell and Sylvester 2012). Finally, this area with NDVI over 0.6 was classified as either broadleaf or conifer forest based on its spectral signature.

In addition, cells above $2,800 \mathrm{~m}$ were removed from the areas that were initially classified as forest, because $2,800 \mathrm{~m}$ is the tree line in the north of Iran. A visual check of the results of this procedure with aerial photographs indicated that this part of the procedure was reasonable. Finally, to improve the classification of agriculture, cells with a slope more than $20 \%$ were removed from the areas originally classified as agriculture (Fig. 8), using our expert

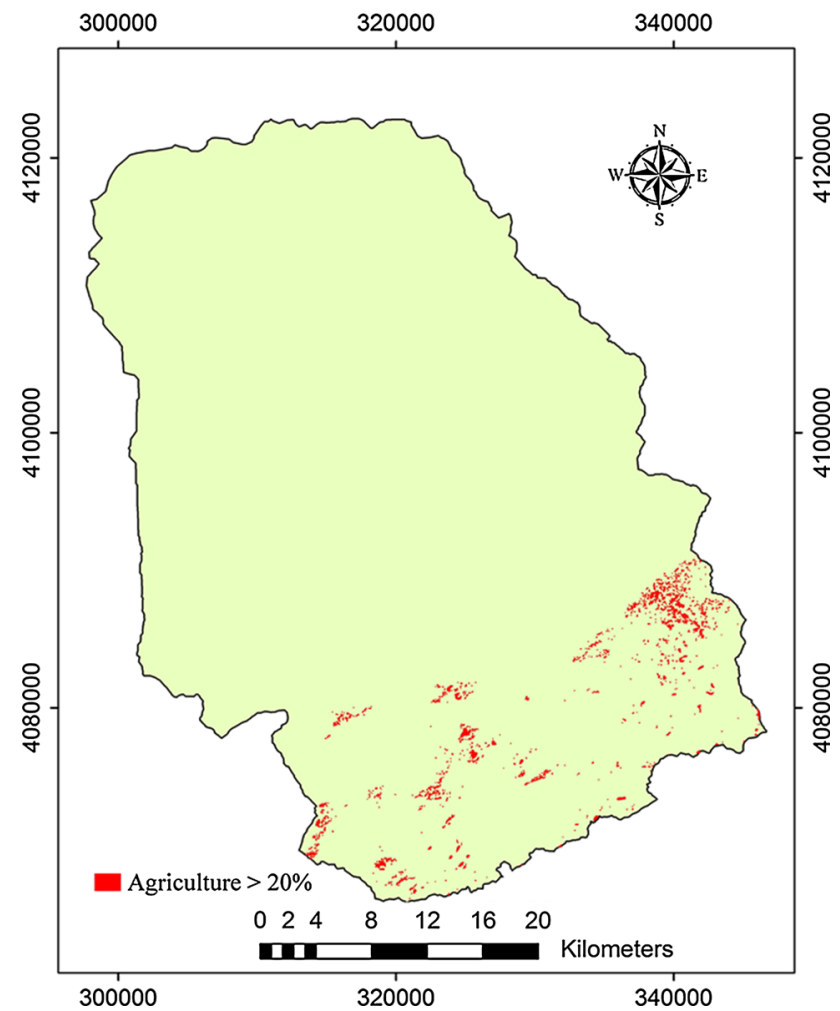

Fig. 8 Agriculture classified in the slope $>20 \%$ in of Baghsalian watershed

knowledge that such steep areas are not cropped. All areas that were forest, residential land or water bodies were considered not agricultural land to solve overlap problems between the supervised and unsupervised classifications. Finally, the remaining unclassified areas were considered rangeland.

\section{Accuracy assessment}

One hundred and twenty signatures were not used for classification and considered for accuracy assessment. These training samples were selected randomly from the full set of 370 signatures. For accuracy assessment, a confusion matrix was calculated (Brandt et al. 2013). From this matrix, two factors can be calculated: the overall classification accuracy and the kappa coefficient. The overall classification accuracy indicates the percentage of cells that were correctly classified. The kappa coefficient is a measure for correspondence corrected for correspondence by chance and was recommended as a standard by Rosenfield and Fitzpatrick-lins (1986). This standard has been widely adopted (Hudson and Ramm 1987; Lillesand and Kiefer 2000; Foody 2002; Bakr et al. 2010; Rozenstein and Karnieli 2010; Abd el-kawy et al. 2011; Rojas et al. 2013; Schmitt-harsh 2013). The USGS proposed a kappa 
Fig. 9 Maximum likelihood classification map of Baghsalian watershed

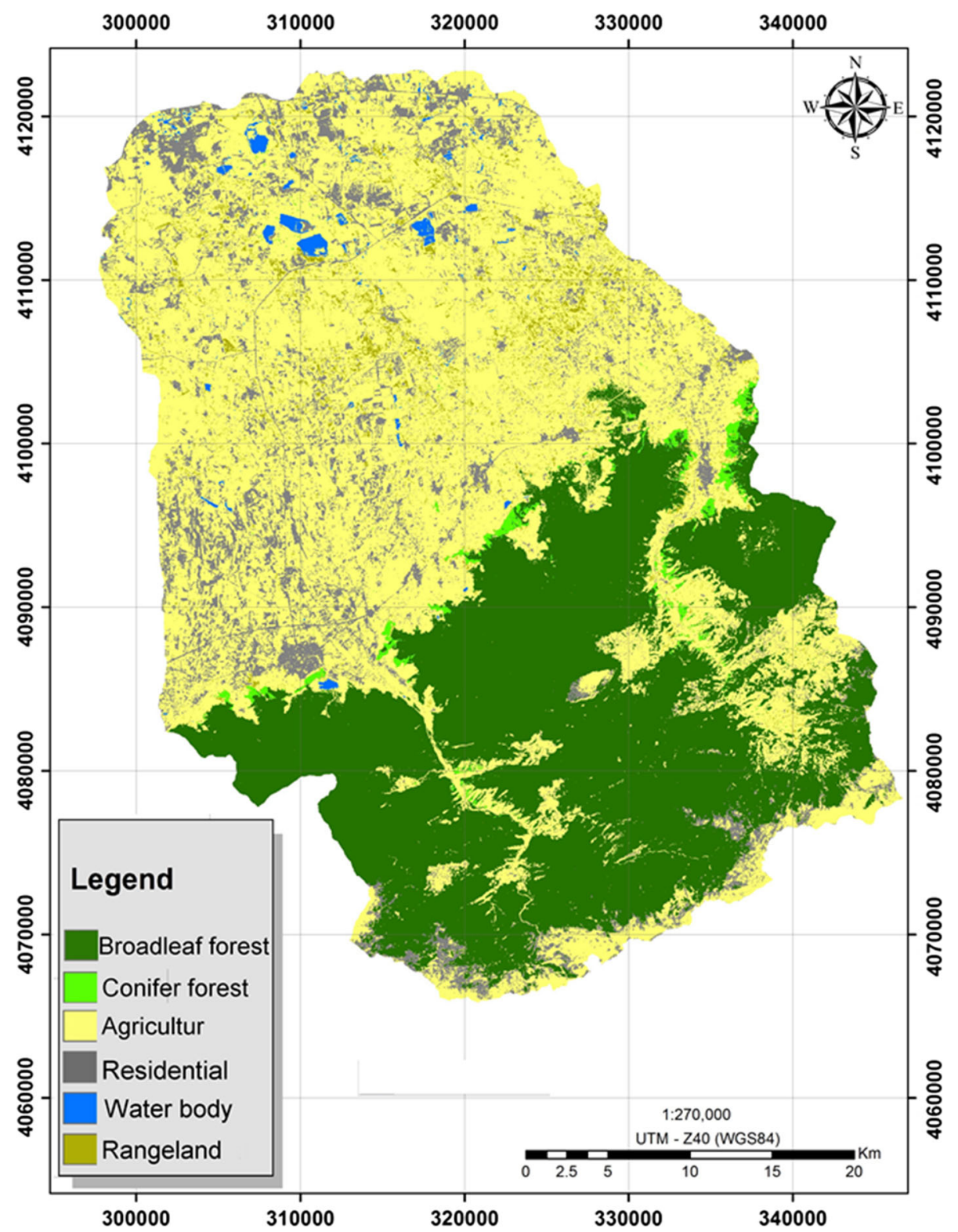

coefficient of $85 \%$ as the minimum requirement for land use/cover mapping with Landsat data (Anderson et al. 1976).

\section{Results and discussion}

A total of 13 land use maps were extracted: 6 unsupervised and 6 supervised maps from each of the individual satellite images and 1 synthetic map combing information from the satellite images. Figure 9 shows an example of a supervised classification result. For all maps, the accuracy was calculated. Table 3 shows these results.

Overall indicates the value for the overall classification accuracy, and kappa indicates the value for the kappa index.
It is clear that results for either the unsupervised or supervised methods are unsatisfactory and that the synthetic map result is satisfactory. Figure 10 shows the land use map resulting after applying the unsupervised, supervised methods and the decision support system (synthetic method).

As shown in Fig. 10, most of the agricultural area is located in the plains in the north of the area and the forest classes and rangeland are mostly in the highlands. Table 4 shows the area of the six land use classes in the synthetic map. The largest class is agriculture, and the smallest class is water bodies.

We applied supervised, unsupervised and synthetic land use classification methods to classify a land use map. The synthetic method that combined maximum likelihood 
Table 3 The accuracy assessment of the 13 calculated land use maps

\begin{tabular}{|c|c|c|c|c|c|c|c|}
\hline \multirow[t]{2}{*}{ Image } & \multirow[t]{2}{*}{ Date } & \multicolumn{2}{|c|}{ Unsupervised } & \multicolumn{2}{|l|}{ Supervised } & \multicolumn{2}{|l|}{ Synthetic } \\
\hline & & Overall (\%) & Kappa & Overall (\%) & Kappa & Overall (\%) & Kappa \\
\hline TM & 2010.4 .3 & 75.6 & 0.69 & 83.6 & 0.80 & 98.2 & 0.98 \\
\hline ETM+ & 2010.5.29 & 78.2 & 0.74 & 84.2 & 0.81 & & \\
\hline TM & 2010.6 .6 & 71.8 & 0.68 & 84.8 & 0.82 & & \\
\hline $\mathrm{TM}$ & 2010.8 .9 & 68.8 & 0.59 & 81.84 & 0.77 & & \\
\hline ETM+ & 2010.8 .17 & 60.2 & 0.61 & 81.17 & 0.77 & & \\
\hline ETM+ & 2010.9 .2 & 58.7 & 0.57 & 82.7 & 0.79 & & \\
\hline
\end{tabular}

Fig. 10 Land use map of Baghsalian watershed prepared with the synthetic method

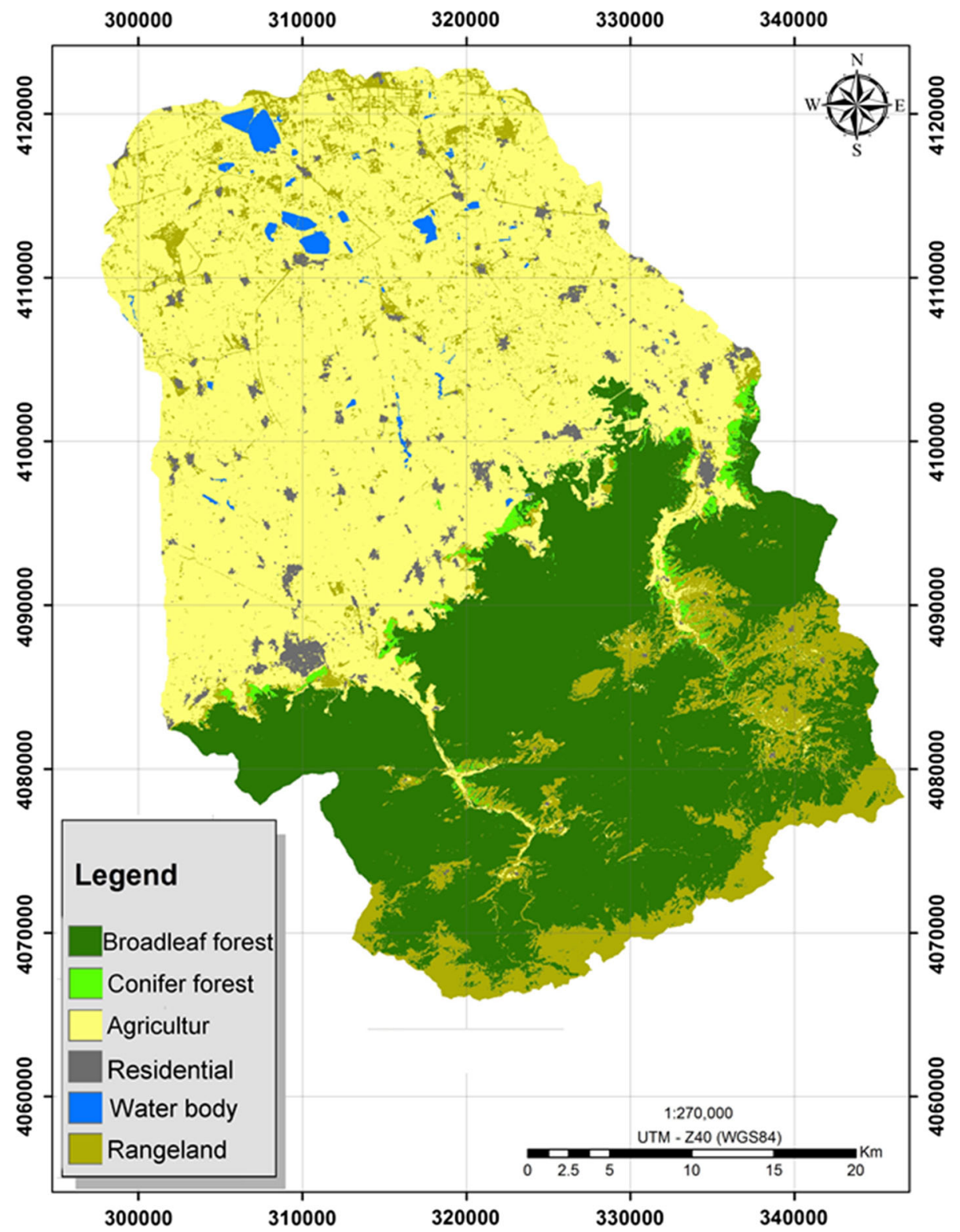

(supervised) classification, ISODATA (unsupervised) classification and an expert knowledge-based decision support system provided a better accuracy than the supervised and unsupervised methods without expert knowledge. The decision support system combined multiple data sources. 
Table 4 Area of land use classes

\begin{tabular}{lcc}
\hline Land use class & Area $\left(\mathrm{km}^{2}\right)$ & Percent \\
\hline Agriculture & 882.197 & 48.23 \\
Broad leaf forest & 643.045 & 35.16 \\
Range & 231.874 & 12.68 \\
Residential area & 39.226 & 2.14 \\
Conifer forest & 17.403 & 0.95 \\
Water body & 15.348 & 0.84 \\
\hline
\end{tabular}

The overall accuracy and kappa coefficient of the synthetic method are both about $98 \%$, which are unusually high values. The kappa coefficient for agriculture, broadleaf forest, conifer, residential area, rangeland and water bodies is 96.6, 98.9, 97.4, 99.4, 96.8 and 99.3, respectively. As mentioned in the previous section, there is a strong mix of agriculture and range classes in the studied watershed. About $60 \%$ of the watershed is covered with these two land use type, and it is therefore essential to correctly separate these classes. Despite including many training samples of crops in different phenological stages, there was still confusion between agricultural land and rangelands using the supervised method (maximum likelihood classification). The basis of supervised classification is the similarity of spectral reflection. Agriculture in the study area is very diverse, and different plants are cultivated. In some areas, there are green plants and plowed fields together, while both of them are agriculture but have different spectral reflection. Therefore in the heterogeneous area, collection of training samples is challenging, and therefore, an unsupervised approach (ISODATA) using several images at the same year is more suitable (Rozenstein and Karnieli 2010). Multiple images in each year allow capturing vegetation peaks in all fields. This technique was previously used by other researchers (Turner and Congalton 1998; Wolter et al. 1995; Prishchepov et al. 2012; Brandt et al. 2013). Forest, residential and water body classes were derived using supervised (maximum likelihood) method. Spectral characteristics of these classes do not change in different season and training samples are useful for classification. Ancillary data such as slope gradient, altitude and NDVI maps were used through a DSS to update the classification. The application of ancillary geographic data within an expert system classification approach based on logical decision rules (Stefanov et al. 2001) has been suggested as a method to yield a more accurate alternative for the classification of landscape features. This has been confirmed in this study: The overall accuracy and kappa coefficient of the land use map produced with the synthetic map are $98.2 \%$ and 0.975 , respectively. The $98.2 \%$ accuracy is significantly higher than the $85 \%$ that has been set as satisfactory for planning and management purposes (Anderson et al. 1976). This contrasts with a value lower than $85 \%$ in several other reported land use classification studies (Foody 2002; Wilkinson 2005). For example, Cingolani et al. (2004) showed overall accuracy and kappa for maximum likelihood $78 \%$ and 0.74 , respectively. In the study of Rozenstein and Karnieli (2010), overall accuracy and kappa coefficient were $70.67 \%$ and 0.65 for ISODATA, $60.53 \%$ and 0.53 for maximum likelihood, 73.50 and 0.68 for synthetic method. Overall accuracy and kappa coefficient in the study of Sun et al. (2011) were $84.89 \%$ and 0.82 for maximum likelihood model. Huang et al. (2010) obtained $85 \%$ and 0.76 for overall accuracy and kappa coefficient. The results of Liu et al. (2011) showed $80 \%$ and 0.7 for overall accuracy and kappa coefficient in the maximum likelihood method. Finally, Rojas et al. 2013 were used maximum likelihood to classify land use map with overall accuracy and kappa coefficient equal to $75 \%$ and 0.78 , respectively; meanwhile, agriculture has minimum accuracy (64\%).

However, other studies have found better results, for example Otukei and Blaschke (2010) applied decision tree, maximum likelihood and support vector machines for classification. Their best method was a decision tree with $94 \%$ and 0.93 for overall accuracy and kappa coefficient. Abd el-kawy et al. (2011) combined maximum likelihood and visual interpretation to improve land use classification. The overall accuracy and kappa coefficient were $95 \%$ and 0.92 , respectively, that shows visual interpretation map can be useful in land use mapping. In the research of Petropoulos et al. (2012), support vector machines showed $94.93 \%$ and 0.937 in the overall accuracy and kappa coefficient. Our results for the synthetic method showed an overall accuracy and kappa coefficient that are higher than in all these other studies. Therefore, it is safe to conclude that the synthetic method has enough accuracy for land use mapping in our study area.

In this respect, it must be noted though that some of our decision rules must be changed if the approach is to be used in other areas. For example, in the Baghsalian watershed, there is no agriculture on slopes over $20 \%$ or at elevations over $2,800 \mathrm{~m}$. These rules are likely to differ between areas. Some of our rules are more constant across regions, for example the rule that only forest can have NDVI over 0.6. Within Iran, many northern regions are similar to the Baghsalian watershed in terms of land use and topography. The method that we used here may well be useful for these areas as well and the authors hope to apply it there in the near future. In addition, the synthetic method used in this study can easily be applied to earlier years to obtain a multi-temporal set of land use maps. 


\section{Conclusion}

There is multi-temporal agriculture in the case study, and there are spectral mixes between agriculture and other land use types. As a result, traditional methods did not have enough accuracy for land use classification in this region. A synthetic method combining supervised and unsupervised classification with a decision support system designed for this study delivers very high classification accuracy and is therefore appropriate to classify land use in our study area.

Acknowledgments The author would like to thank the Tarbiat Modares University for financial support. The authors also are grateful to spatial academy (www.spatialacademy.com) team for technical support in GIS and remote sensing.

\section{References}

Abd el-kawy OR, Ismail HA, Suliman AS (2011) Land use and land cover change detection in the western Nile delta of Egypt using remote sensing data. Appl Geogr 31(2):483-494

Alesheikh AA, Ghorbanali A, Nouri N (2007) Coastline change detection using remote sensing. Int $\mathrm{J}$ Environ Sci Technol 4(1):61-66

Alrababah MA, Alhamad MN (2006) Land use/cover classification of arid and semi-arid mediterranean landscapes using Landsat ETM. Int J Remote Sens 27(13):2703-2718

Anderson JR, Hardy EE, Roach JT, Witmer RE (1976) A land use and land cover classification system for use with remote sensor data. U.S. Geological survey, Washington, DC, No. Professional paper 964

Bakr N, Weindorf DC, Bahnassy MH, Marei SM, El-badawi MM (2010) Monitoring land cover changes in a newly reclaimed area of Egypt using multitemporal Landsat data. Appl Geogr 30(4):592-605

Brandt JS, Haynes MA, Kuemmerle T, Waller DM, Radeloff VC (2013) Regime shift on the roof of the world: alpine meadows converting to shrublands in the southern Himalayas. Biol Conserv 158:116-127

Cetin M (2009) A satellite based assessment of the impact of urban expansion around a lagoon. Int $\mathbf{J}$ Environ Sci Technol 6(4):579-590

Chen J, Zhu X, Vogelmann JE, Gao F, Jin S (2011) A simple and effective method for filling gaps in Landsat ETM+ slc-off images. Remote Sens Environ 115(4):1053-1064

Cingolani AA, Renison D, Zak MR, Cabido MR (2004) Mapping vegetation in a heterogeneous mountain rangeland using Landsat data: an alternative method to define and classify land-cover units. Remote Sens Environ 92(1):84-97

Cohen WB, Goward SN (2004) Landsat's role in ecological applications of remote sensing. Bioscience 54(6):535-545

Foody GM (2002) Status of land cover classification accuracy assessment. Remote Sens Environ 80(1):185-201

Golestan Regional Water Co (2007) Golestan province meteorological information report

Hansen MC, Roy DP, Lindquist E, Adusei B, Justice CO, Altstatt A (2008) A Method for integrating Modis and Landsat data for systematic monitoring of forest cover and change in the Congo basin. Remote Sens Environ 112(5):2495-2513

Huang C, Goward SN, Masek JG, Thomas N, Zhu Z, Vogelmann JE (2010) An automated approach for reconstructing recent forest disturbance history using dense Landsat time series stacks. Remote Sens Environ 114(1):183-198

Hudson W, Ramm C (1987) Correct formula of the kappa coefficient of agreement. Photogramm Eng Remote Sens 53(4):421-422

Koutsias N, Karteris M (2003) Classification analyses of vegetation for delineating forest fire fuel complexes in a Mediterranean test site using satellite remote sensing and GIS. Int J Remote Sens 24(15):3093-3104

Lillesand TM, Kiefer RW (2000) Remote sensing and image interpretation. Wiley, New York, p 724

Liu K, Shi W, Zhang H (2011) A fuzzy topology-based maximum likelihood classification. J Photogramm Remote Sens 66(1):103-114

Manandhar R, Odeh IOA, Ancev T (2009) Improving the accuracy of land use and land cover classification of Landsat data using postclassification enhancement. Remote Sens 1(13):330-344

Masek JG, Huang CQ, Wolfe R, Cohen W, Hall F, Kutler J, Nelson V (2008) North American forest disturbance mapped from a decadal Landsat record. Remote Sens Environ 112(6):2914-2926

Maxwell SK, Sylvester KM (2012) Identification of "ever-cropped" land (1984-2010) using Landsat annual maximum NDVI image composites: southwestern Kansas case study. Remote Sens Environ 121:186-195

Mohammady M, Pourghasemi HR, Pradhan B (2012) Landslide susceptibility mapping at Golestan province, Iran: a comparison between frequency ratio, Dempster-Shafer, and weights-ofevidence models. J Asian Earth Sci 61:221-236

Mohammady M, Moradi HR, Zeinivand H, Temme AJAM, Pourghasemi HR, Alizadeh H (2013) Validating gap-filling of Landsat ETM + satellite images in the Golestan Province, Iran, Arabian. J Geosci. doi:10.1007/s12517-013-0967-5

Otukei JR, Blaschke T (2010) Land cover change assessment using decision trees, support vector machines and maximum likelihood classification algorithms. Int J Appl Earth Obs 12(1):27-31

Petropoulos P, Kontoes C, Keramitsoglou I (2012) Land cover mapping with emphasis to burnt area delineation using co-orbital ali and Landsat TM imagery. Int J Appl Earth Obs 18:344-355

Prishchepov AV, Radeloff VC, Dubinin M, Alcantara C (2012) The effect of Landsat ETM/ETM+ image acquisition dates on the detection of agricultural land abandonment in eastern Europe. Remote Sens Environ 126:195-209

Rojas C, Pino J, Basnou C, Vivanco M (2013) Assessing land-use and -cover changes in relation to geographic factors and urban planning in the metropolitan area of concepcion (Chile). Implications for biodiversity conservation. Appl Geogr 39:93-103

Rosenfield G, Fitzpatrick-lins K (1986) A coefficient of agreement as a measure of thematic classification accuracy. Photogramm Eng Remote Sens 52(2):223-227

Rozenstein O, Karnieli A (2010) Comparison of methods for land-use classification incorporating remote sensing and GIS inputs. Appl Geogr 31(2):533-544

Schmitt-harsh M (2013) Landscape change in Guatemala: driving forces of forest and coffee agroforest expansion and contraction from 1990 to 2010. Appl Geogr 40:40-50

Schulz J, Cayuela L, Echeverria C, Salas J, Rey Benayas JM (2010) Monitoring land cover change of the dryland forest landscape of central Chile (1975-2008). Appl Geogr 30(3):436-447

Sexton JO, Urban DL, Donohue MJ, Song C (2013) Long-term land cover dynamics by multi-temporal classification across the Landsat-5 record. Remote Sens Environ 128:246-258

Shalaby A, Tateishi R (2007) Remote sensing and GIS for mapping and monitoring land cover and land-use changes in the northwestern coastal zone of Egypt. Appl Geogr 27(1):28-41

Stefanov WL, Ramsey MS, Christensen PR (2001) Monitoring urban land cover change: an expert system approach to land cover 
classification of semiarid to arid urban centers. Remote Sens Environ 77(2): 173-185

Sun J, Yang J, Zhang C, Yun W, Qu J (2011) Automatic remotely sensed image classification in a grid environment based on the maximum likelihood method. Math Comput Model. doi:10. 1016/j.mcm.2011.10.063

Turner MD, Congalton RG (1998) Classification of multi-temporal spot-xs satellite data for mapping rice fields on a West African floodplain. Int J Remote Sens 19(1):21-41

Wang J, Rich PM, Price KP, Kettle WD (2005) Relations between NDVI, grassland production, and crop yield in the central Great Plains. Geocarto Int 20(3):5-11

Wilkinson GG (2005) Results and implications of a study of fifteen years of satellite image classification experiments. IEEE Geosci Remote Sens 43(3):433-440
Wolter PT, Mladenoff DJ, Host GE, Crow TR (1995) Improved forest classification in the northern lake states using multi-temporal Landsat imagery. Photogramm Eng Remote Sens 61(9):1129-1144

Yiqiang G, Yanbin W, Zhengshan J, Jun W, Luyan Z (2010) Remote sensing image classification by the chaos genetic algorithm in monitoring land use changes. Math Comput Model 51(11):1408-1416

Zegre NP, Maxwell A, Lamont A (2013) Characterizing stream flow response of a mountaintop-mined watershed to changing land use. Appl Geogr 39:5-15 